\title{
The APC/C inhibitor, Emi1, is essential for prevention of rereplication
}

\author{
Yuichi J. Machida and Anindya Dutta ${ }^{1}$ \\ Department of Biochemistry and Molecular Genetics, University of Virginia School of Medicine, \\ Charlottesville, Virginia 22908, USA
}

\begin{abstract}
Emi1 (early mitotic inhibitor) inhibits APC/C (anaphase-promoting complex/cyclosome) activity during S and G2 phases, and is believed to be required for proper mitotic entry. We report that Emi1 plays an essential function in cell proliferation by preventing rereplication. Rereplication seen after Emil depletion is due to premature activation of APC/C that results in destabilization of geminin and cyclin A, two proteins shown here to play redundant roles in preventing rereplication in mammalian cells. Geminin is known to inhibit the replication initiation factor $\mathrm{Cdt1}$. The rereplication block by cyclin $\mathrm{A}$ is mediated through its association with $S$ and G2/M cyclin-dependent kinases (Cdks), Cdk2 and Cdk1, suggesting that phosphorylation of proteins by cyclin A-Cdk is responsible for the block. Rereplication upon Emi1 depletion activates the DNA damage checkpoint pathways. These data suggest that Emi1 plays a critical role in preserving genome integrity by blocking rereplication, revealing a previously unrecognized function of this inhibitor of APC/C.
\end{abstract}

[Keywords: APC/C; Cdk; cyclin A; Emil; geminin; rereplication]

Supplemental material is available at http://www.genesdev.org.

Received September 20, 2006; revised version accepted November 27, 2006.

DNA replication initiates from the specific regions of chromosomal DNA called origins. A critical question in the field of genomic stability is how cells manage to restrict the firing of origins to once and only once per cell cycle. Not only is this regulation achieved despite the fact that thousands of origins fire asynchronously all over the genome, but the regulation is selectively breached during certain stages of development as in endoreduplicating trophoblasts. Most of this regulation appears to be executed at the level of prereplicative complex (pre-RC) formation or origin licensing. The origin recognition complex (ORC) recruits Cdc6 and Cdt1 to origins in G1, which in turn load the putative replicative helicase, Mcm2-7, to form pre-RCs (for review, see Machida et al. 2005a). After replication initiation in the subsequent $\mathrm{S}$ phase, $\mathrm{Mcm} 2-7$ are depleted from origins, but reformation of pre-RCs is prevented until chromosomes are segregated in $M$ phase. Higher eukaryotes, including human cells, express geminin (McGarry and Kirschner 1998) a protein that binds to Cdt1 to prevent loading of Mcm2-7 on post-initiation origins (Wohlschlegel et al. 2000; Tada et al. 2001). Knockdown of geminin by RNA interference (RNAi) is sufficient to induce rereplication in many human cell lines (Melixetian et al. 2004; Zhu et al. 2004), and geminin-null mice show enhanced endoreduplication in trophoblasts of early embryos (Gonzalez

${ }^{1}$ Corresponding author.

E-MAIL ad8q@virginia.edu; FAX (434) 924-5069.

Article is online at http://www.genesdev.org/cgi/doi/10.1101/gad.1495007. et al. 2006). These results suggest that geminin is a major inhibitor of rereplication in mammalian cells. Yeast, however, do not encode geminin, and rereplication is prevented solely by the high levels cyclin-dependent kinase (Cdk) activity seen during S and G2 phases of the cell cycle (Correa-Bordes and Nurse 1995; Nguyen et al. 2001; Wilmes et al. 2004; for review, see Machida et al. 2005a). A role of high Cdk activity in rereplication block has also been suggested in human cells (Itzhaki et al. 1997), although cancer cells that show rereplication after geminin knockdown do so without any obvious mechanism to concurrently inhibit Cdk2 activity. It is therefore currently unclear whether geminin and Cdk play redundant roles in rereplication block, or whether these mechanisms function in different parts of the cell cycle or in different tissues.

The regulated degradation of proteins by proteasomes through a carefully orchestrated polyubiquitination program is a critical component of cell cycle regulation. For example, Cdks are important for progression through $S$, $\mathrm{G} 2$, and $\mathrm{M}$, but their activity is regulated by the periodic accumulation and destruction of different types of cyclins. Levels of cyclins in the cell cycle are regulated by two ubiquitin ligases, SCF and anaphase-promoting complex/cyclosome (APC/C). SCF complex uses an Fbox protein as a substrate recognition subunit. For example, $\mathrm{SCF}^{\mathrm{FBXW} 7}$ polyubiquitinates the G1 cyclin, cyclin E, for degradation in $S$ phase. There are $>60$ F-box proteins in the human genome but the cellular functions of most of them are not yet known (Jin et al. 2004). APC/C, 
on the other hand, uses substrate recognition subunits Cdc20 and Cdh1 to polyubiquitinate substrates like cyclins $\mathrm{A}$ and $\mathrm{B}$ (and geminin) in mitosis and the subsequent G1. Cdc20 activates APC/C in mitosis while Cdh1 activates $\mathrm{APC} / \mathrm{C}$ in late $\mathrm{M}$ and $\mathrm{G} 1$ phases. Both these subunits target substrates by recognizing a destruction motif called D-box (Glotzer et al. 1991; Fang et al. 1998), while Cdh1, in addition, recognizes a KEN-box (Pfleger and Kirschner 2000).

Since cyclin A/Cdk kinase activity is essential for DNA replication, the inactivation of $\mathrm{APC} / \mathrm{C}$ at the $\mathrm{G} 1 / \mathrm{S}$ transition is critical for the accumulation of cyclin A for S-phase progression. Emil (early mitotic inhibitor) is a cellular inhibitor of APC/C that is not present in yeasts, and is induced by the E2F transcription factor to inactivate APC/C at the G1/S transition (Reimann et al. 2001; Hsu et al. 2002). Emil-mediated reduction in APC/C activity allows cells to accumulate cyclin $\mathrm{A}$, and then the accumulated cyclin A-Cdk complex in S phase further suppresses APC/C activity by phosphorylating Cdh1 (Lukas et al. 1999; Sorensen et al. 2001). Because of its role in suppression of $\mathrm{APC} / \mathrm{C}$ and because the latter is critical for mitosis, the primary role of Emil is believed to ensure proper mitotic entry. At the onset of mitosis, Emil is degraded following phosphorylation by Plk1 and ubiquitination by SCF ${ }^{\beta-T r C P}$ (Guardavaccaro et al. 2003; Margottin-Goguet et al. 2003; Hansen et al. 2004; Moshe et al. 2004), and this allows the activation of APC/C that is critical for progression through $M$ phase and the subsequent G1 phase.

Since SCF is involved in many aspects of cell cycle regulation, we initiated a search for F-box proteins that are required for cell proliferation by RNAi screening. This screen identified Emil, an F-box protein known as FBXO5, to be essential for cell proliferation. Surprisingly, the block to cell proliferation was accompanied by extensive rereplication after Emil depletion. This rereplication is due to premature activation of APC/C in S and G2 cells. Among many APC/C substrates, we show that cyclin A and geminin are critical for prevention of rereplication, and that the two proteins act simultaneously in $\mathrm{S}$ and G2 cells as redundant barriers to rereplication. These data suggest that an essential function of Emil in $\mathrm{S}$ and G2 cells is to prevent rereplication via stabilization of inhibitors of rereplication such as cyclin A and geminin.

\section{Results}

RNAi screening for F-box proteins required for cell proliferation

We previously developed a simple method to screen for genes required for cell proliferation by RNAi (Machida et al. 2006). We have initiated a search for F-box proteins involved in cell cycle regulation, by using small interfering RNA (siRNA) duplexes against each of 66 human F-box proteins. Each siRNA duplex was transfected into a breast epithelial cell line, MCF10A, in a 96-well format and effect on cell proliferation assessed by measuring BrdU incorporation after $3 \mathrm{~d}$ (Y. Machida and A. Dutta, unpubl.). For genes that were essential for cell proliferation in the primary screen, second siRNAs targeting another part of mRNA were designed and used in a secondary RNAi screen. FBXO5, which is also known as the APC inhibitor, Emil, was one of the F-box proteins whose knockdown reduced BrdU incorporation in both primary and secondary screens (Supplementary Fig. 1), suggesting that Emil plays an essential role in cell proliferation.

\section{Emi1 RNAi causes rereplication in human cells}

We first confirmed that the Emil siRNA oligo (siEmil. 582), which was used for the siRNA screening, knocked down Emil protein levels in MCF10A by Western blot (Fig. 1A). Emil depletion is known to cause premature degradation of mitotic cyclins, and result in defects
A
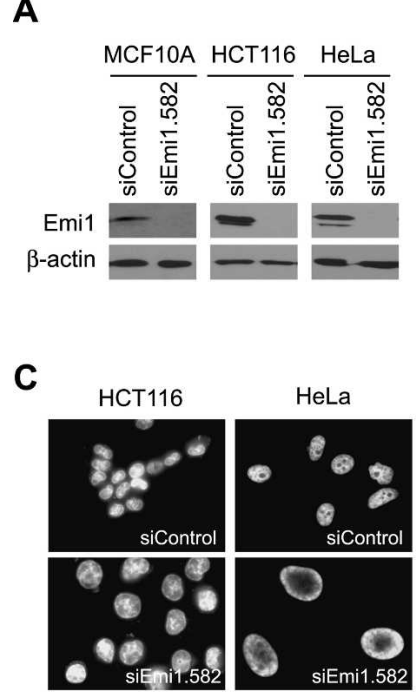

B

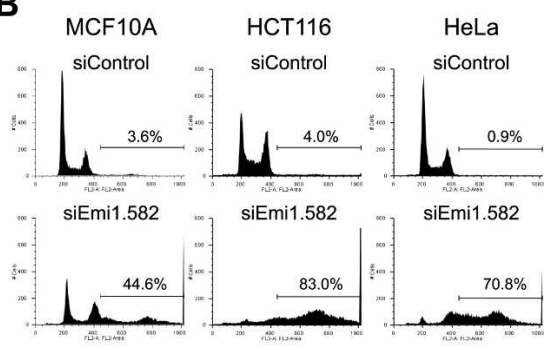

D

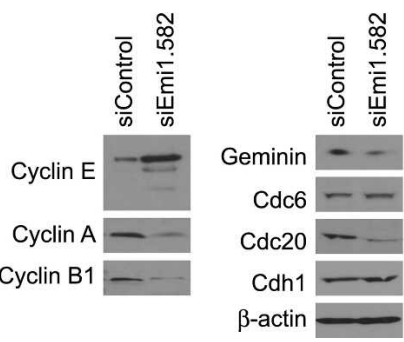

Figure 1. Emil depletion causes rereplication accompanied by a decrease in cyclin $\mathrm{A}$ and geminin. $(A)$ Emil depletion by Emil RNAi. MCF10A, HCT116, and HeLa were transfected with siControl or siEmil oligos, and Emil protein levels were examined by Western blotting. $\beta$-Actin is shown as a loading control. (B) Emil depletion causes rereplication. MCF10A, HCT116, and HeLa were transfected with siControl or siEmil oligos, and the DNA content of the cells was examined by FACS. The percentages of cells with $>4$ N DNA content are indicated. $(C)$ Emil depletion results in giant nuclei. HCT116 and HeLa transfected with siControl or siEmil duplexes were examined under a microscope after staining DNA with DAPI. $(D)$ APC/C substrates are decreased after Emil RNAi in HeLa. Levels of indicated proteins were assessed by Western blotting. 
in entry into $\mathrm{S}$ or $\mathrm{M}$ phases (Reimann et al. 2001; Grosskortenhaus and Sprenger 2002; Hsu et al. 2002; Lee et al. 2006). To test if failure to enter $S$ or $M$ phases is the reason for reduced cell proliferation, we examined the cell cycle status of Emil-depleted cells by FACS analysis. If the essential role of Emil in cell proliferation is in S- or M-phase entry, Emil-depleted cells are expected to accumulate with $2 \mathrm{~N}$ or $4 \mathrm{~N}$ DNA content, respectively. However, RNAi of Emil instead caused rereplication in MCF10A as revealed by the accumulation of cells with $>4 N$ DNA content (Fig. 1B). Similarly, rereplication was seen after Emil depletion in other cell lines such as a colon cancer cell line, HCT116, and a cervical cancer cell line, HeLa (Fig. 1A,B). Since rereplication was observed in the nontransformed cell line, MCF10A, the requirement of Emil for rereplication block is not restricted to cancer-derived cell lines. Two additional siRNA duplexes (siEmil.1298 and siEmil.1411) targeting different sequences of the Emil mRNA also caused rereplication (Supplementary Fig. 2). Previously we have reported that the size of nuclei correlates with the degree of rereplication after geminin depletion (Zhu et al. 2004). Emil depletion also resulted in giant nuclei in HCT116 and HeLa (Fig. 1C). In summary, these results suggest that Emil is critical to prevent rereplication in human cells.

The known function of Emil is inhibition of APC/C in $\mathrm{S}$ and $\mathrm{G} 2$ phases. APC/C substrates including cyclin $\mathrm{A}$, cyclin B1, geminin, and Cdc20 were decreased after Emil RNAi (Fig. 1D), suggesting that APC/C is prematurely activated in these cells. In contrast, the protein level of another APC/C substrate involved in replication initiation, Cdc6, remained unchanged. Cyclin E levels are elevated in Emil-depleted cells probably due to increased E2F-dependent transcription upon APC/C activation (Sorensen et al. 2000). Since cyclin E-Cdk2 protects Cdc6 from APC/C (Mailand and Diffley 2005), the elevated cyclin E protein level in Emil-depleted cells could explain the lack of any decrease of Cdc6. The proteasome inhibitor, MG132, blocked decrease of geminin and cyclin A (Supplementary Fig. 3), consistent with the idea that these proteins are targeted for degradation by proteasomes after Emil RNAi.

To rule out the possibility that rereplication seen after Emil RNAi is due to off-target activity, we tested whether the rereplication phenotype is suppressed by exogenous expression of Flag-tagged Emil. Seven silent mutations were introduced to the target sequence of siEmi1.582 to make the exogenous Emil resistant to siRNA (Flag-Emil ${ }^{\text {SR }}$; SR for siRNA resistant) (Fig. 2A). In addition, Flag-Emil ${ }^{\text {SR }}$ was expressed from the coding sequence of Emil so that Flag-Emil ${ }^{\mathrm{SR}}$ is resistant to siEmil.1411, whose target site is in the 3'UTR of Emil mRNA. Expression of Flag-Emil ${ }^{\text {SR }}$ restored the amount of Emil in cells treated with siEmil.582 and siEmil.1411 and prevented reduction of APC/C substrates, cyclin $\mathrm{A}$ and geminin (Fig. 2B). These cells did not undergo rereplication (Fig. 2C), confirming that rereplication is a specific effect of Emil knockdown.
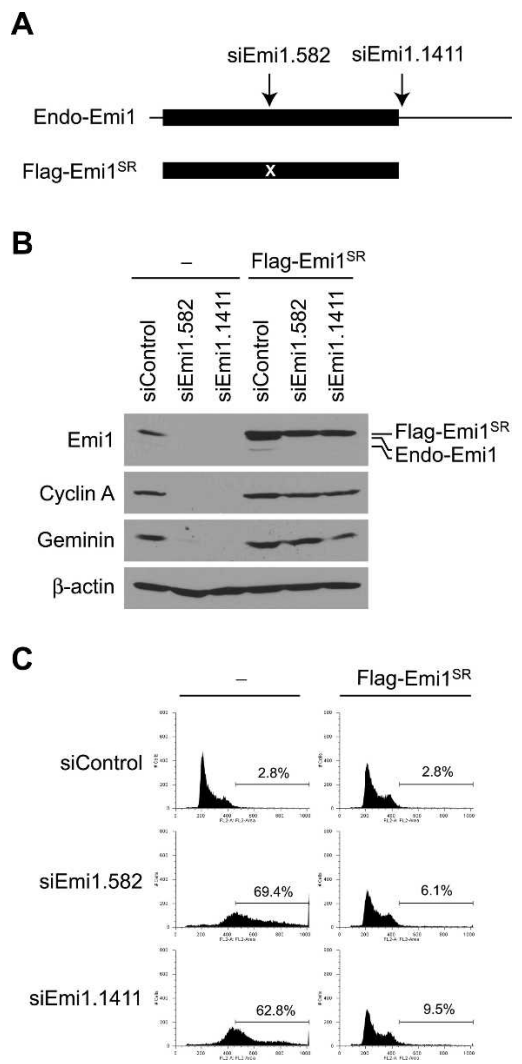

Figure 2. Rescue of Emil RNAi phenotype in cells stably expressing siRNA-resistant Emil. (A) Schematic diagrams of endogenous Emil mRNA (Endo-Emi1) and the region expressed exogenously (Flag-Emil ${ }^{\mathrm{SR}}$ ). Flag-Emil ${ }^{\mathrm{SR}}$ is expressed from the coding sequence of Emil, and contains seven silent mutations in the siEmi1.582 target sequence (marked as " $\mathrm{X}$ "). Since the exogenous Emil does not possess the 3'UTR sequence, its expression is also not affected by siEmi1.1411, whose target site is in the 3'UTR. Black boxes and lines indicate the Emil coding sequence and UTRs, respectively. (B) Restoration of Emil levels by exogenous Emil. HeLa cells were infected with retroviruses expressing Flag-Emil ${ }^{\mathrm{SR}}$. The cells were transfected with siRNAs $(48 \mathrm{~h})$, and the indicated proteins were examined by Western blotting. (Endo-Emil) Endogenous Emil. (C) Suppression of rereplication after Emil RNAi by Flag-Emil ${ }^{\text {SR }}$ expression. HeLa cells with or without Flag-Emil ${ }^{\text {SR }}$ expression were transfected with the indicated siRNAs and rereplication was analyzed by FACS for DNA content. The percentages of cells with $>4 \mathrm{~N}$ DNA are indicated.

\section{Rereplication in Emi1-depleted cells is due to unscheduled activation of $A P C / C^{C d h 1}$}

We next tested whether rereplication in Emil-depleted cells is due to failure to suppress APC/C activity. We codepleted the activator subunits of $\mathrm{APC} / \mathrm{C}, \mathrm{Cdh} 1$, or Cdc20, with Emil. Cdh1 depletion partially restored the levels of APC/C substrates such as cyclin A and geminin, whereas Cdc20 depletion did not (Fig. 3A), indicating that cyclin A and geminin are degraded via the APC/ $\mathrm{C}^{\mathrm{Cdh} 1}$-dependent pathway. The failure of Cdc20 codepletion to restore cyclin A and geminin levels is consistent with the fact that Cdc20 is decreased in Emil-depleted 
A

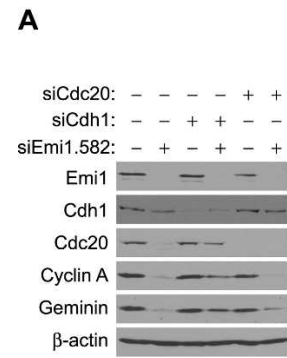

C

Synchronization by Nocodazole

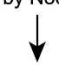

RNAi and release

into Aphidicolin for $24 \mathrm{hr}$

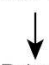

Release from aphidicolin ( $0 \mathrm{hr})$
B
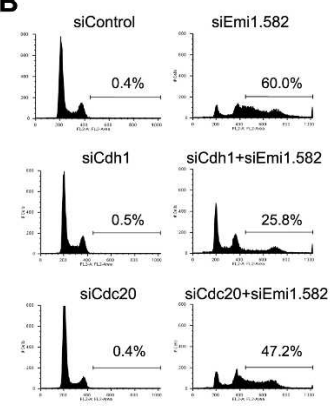

D

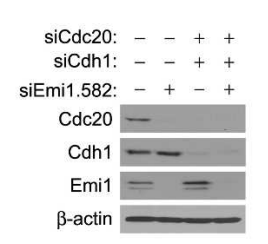

E

E siControl siEmi1.582 siCdh1+siCdc20 siCdh1+siCdc20

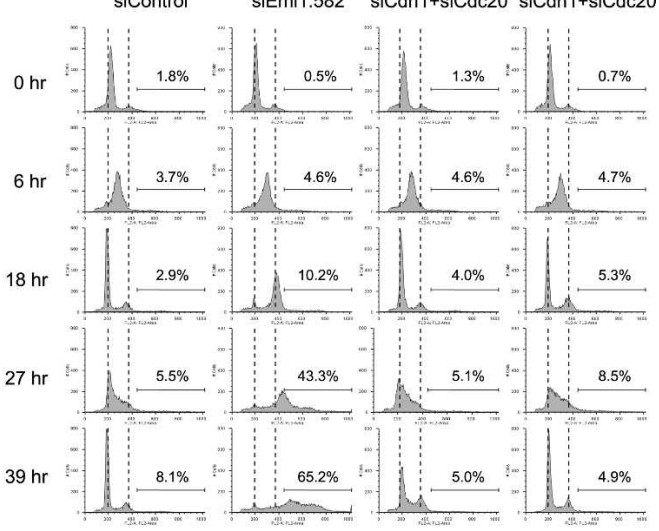

$\mathbf{F}$

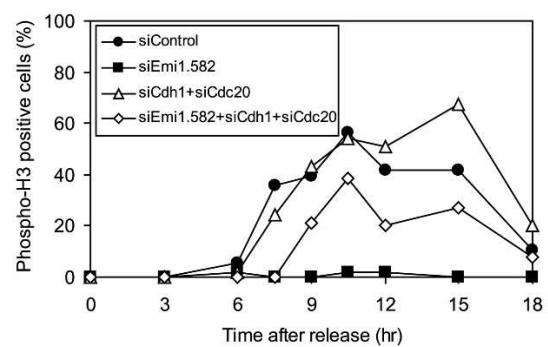

Figure 3. Rereplication in the Emil-depleted cells is APC/C ${ }^{C d h} 1$ dependent. $(A)$ Codepletion of Cdh1 and/or Cdc20 with Emil by RNAi in HeLa. The indicated proteins in RNAi-treated cells were examined by Western blotting. (B) Rereplication after Emil depletion requires Cdh1. HeLa cells transfected with the indicated siRNAs were analyzed by FACS for DNA content. The percentages of cells with $>$ 4N DNA are indicated. $(C)$ Experimental scheme of RNAi in cells synchronized in mitosis. Cells released from the aphidicolin block were sampled at the times indicated in $E$ and $F$. $(D)$ Codepletion of Cdh1 and Cdc20 with Emil by RNAi using the protocol in $C$. Cells released from the aphidicolin block for $27 \mathrm{~h}$ were examined by Western blotting. (E) Emil depletion causes rereplication in an APC/C-dependent manner. HeLa cells treated as in $C$ and released for the indicated times were analyzed by FACS for DNA content. Broken lines indicate the positions of $2 \mathrm{~N}$ and $4 \mathrm{~N}$ peaks in asynchronous cells. The percentages of cells with $>4 \mathrm{~N}$ DNA are indicated. $(F)$ Emil depletion causes rereplication without cells entering mitosis. HeLa cells treated as in $C$ and released for the indicated times were immunostained with an anti-phospho-histone $\mathrm{H} 3$ (mitosis marker) antibody, and the percentages of stained cells are shown.

cells because of degradation by APC/C Cdh1 (Figs. 1D, 3A). Cdh1 depletion suppressed rereplication in Emildepleted cells, whereas Cdc20 depletion did so minimally (Fig. 3B), indicating that rereplication after Emil RNAi is caused via APC/C $\mathrm{C}^{\mathrm{Cdh} 1}$ activation. RNAi of Cdh1 or Cdc20 did not affect the cell cycle profile by itself (Fig. 3B), suggesting that suppression of rereplication is not due to failure of mitosis. To confirm this, we codepleted Cdh1 and Cdc20 with Emil in cell cycle-synchronized cells by the procedure shown in Figure 3C. Cells released from Nocodazole block were transfected with siRNAs and cultured in the media containing aphidicolin, an inhibitor of DNA polymerase $\alpha$. Thus, the cells were held at the G1/S transition while the targeted proteins are depleted. Subsequent release of the cells from the aphidicolin block allowed us to follow the cell cycle progression in the absence of the depleted proteins (Fig. 3D,E). Cells treated with control siRNA entered $\mathrm{S}$ phase, passed through mitosis, and returned to G1 after $18 \mathrm{~h}$. In contrast, Emil-depleted cells continued replication and accumulated DNA $>4 \mathrm{~N}$ after $39 \mathrm{~h}$. Cells depleted of both Cdh1 and Cdc20 showed cell cycle progression similar to control cells except for a slight delay in mitotic exit (Fig. 3F). Cdh1 is dispensable for cell pro- liferation (Sudo et al. 2001), while Cdc20 is believed to be essential for mitosis. The lack of a greater effect of $\mathrm{Cdc} 20$ RNAi on mitosis is most likely because RNAi leaves sufficient proteins in the cells to allow the mitotic function of APC/C. Cdh1 and Cdc20 codepletion, however, suppressed rereplication caused by Emil RNAi, strengthening our conclusion that Emil RNAi induces rereplication through APC/C activation.

\section{Emi1-depleted cells undergo rereplication in the absence of mitosis}

Rereplication caused by repeated replication initiation in $\mathrm{S}$ and G2 phases is clearly different from that produced by cells entering the next cell cycle without chromosome segregation (abortive mitosis). To test whether the Emi1-depleted cells rereplicated in S and G2, we examined whether the cells enter mitosis prior to rereplication. Phosphorylation of histone H3 at Ser10, which is an early mitotic marker, was examined in Emil-depleted cells released from aphidicolin arrest (Fig. 3F). While control siRNA-treated cells became phospho-histone $\mathrm{H} 3$-positive starting at $7.5 \mathrm{~h}$ after release, Emil-depleted cells did not have this mitotic marker during this period. 
Mitotic entry was partially restored by codepletion of Cdh1 and Cdc20 with Emil. These results suggest that Emil causes rereplication without the cells entering mitosis. Phosphorylation of histone $\mathrm{H} 3$ at Ser10 initiates in pericentromeric heterochromatin as foci in late G2 phase (Hendzel et al. 1997). We did not observe such phospho-histone H3 foci either in Emil-depleted cells.

Cyclin $A$ and geminin are relevant $A P C / C$ substrates involved in prevention of rereplication in some cells

The results described above suggest that Emil suppresses rereplication through stabilization of rereplication inhibitors that are APC/C substrates. Geminin is a good candidate for such a protein since it was shown previously that geminin RNAi in HCT116 causes accumulation of cells with DNA $>4 \mathrm{~N}$ (Fig. 4A,B; Melixetian et al. 2004; Zhu et al. 2004). However, in HeLa and MCF10A, depletion of geminin did not induce rereplication even though the knockdown of geminin was as efficient as in HCT116 (Fig. 4A,B), suggesting that, in addition to geminin, there must be other APC/C substrates that block rereplication in these two cell lines. We therefore systematically codepleted APC/C substrates and
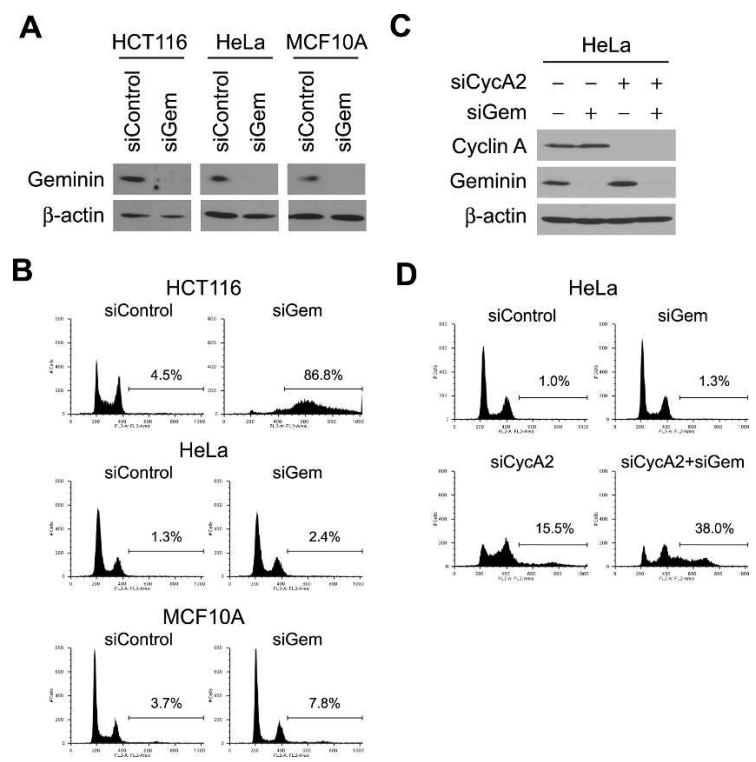

Figure 4. Cyclin A and geminin prevent rereplication in HeLa. (A) Geminin depletion by geminin RNAi. HCT116, HeLa, and MCF10A were transfected with siControl or siGem oligos and geminin protein levels were examined by Western blotting. $\beta$-Actin is shown as a loading control. $(B)$ Geminin depletion is sufficient to induce rereplication in HCT116 but not in HeLa and MCF10A. Cells transfected with siControl or siGem oligos were examined by FACS for DNA content. The percentages of cells with $>4$ N DNA are indicated. $(C)$ Codepletion of cyclin A2 and geminin by RNAi in HeLa. The indicated proteins in RNAitreated cells were examined by Western blotting. $(D)$ Cyclin A2, in addition to geminin, needs to be depleted to induce rereplication in HeLa. Cells transfected with the indicated siRNAs were examined by FACS for DNA content. The percentages of cells with $>4 \mathrm{~N}$ DNA are indicated.
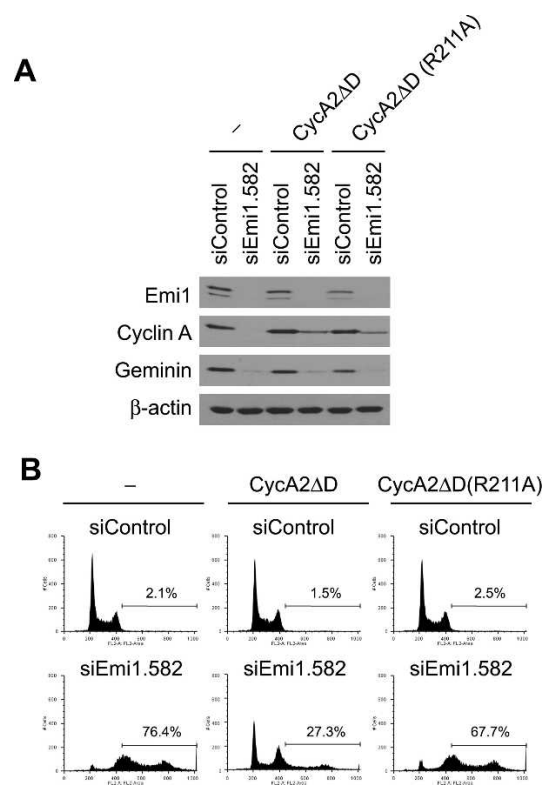

Figure 5. Nondegradable cyclin A2 can suppress rereplication induced by Emil RNAi in a Cdk-binding-dependent manner. $(A)$ Emil RNAi in HeLa cells infected with empty retroviruses (lanes), cyclin $\mathrm{A} 2 \Delta \mathrm{D}$, or cyclin $\mathrm{A} 2 \Delta \mathrm{D}(\mathrm{R} 211 \mathrm{~A})$ viruses. The indicated proteins were examined by Western blotting. $(B)$ Expression of cyclin $\mathrm{A} 2 \Delta \mathrm{D}$ is sufficient to block rereplication caused by Emil depletion. HeLa cells infected with empty retroviruses (- panels), cyclin $\mathrm{A} 2 \Delta \mathrm{D}$, or cyclin $\mathrm{A} 2 \Delta \mathrm{D}(\mathrm{R} 211 \mathrm{~A})$ retroviruses. Cells treated with the indicated RNAi were examined by FACS for DNA content. The percentages of cells with $>4 \mathrm{~N}$ DNA are indicated.

geminin from HeLa cells looking for induction of rereplication. Among cyclins A1, A2, B1, and B2, depletion of cyclin A2 with geminin induced rereplication in HeLa (Fig. 4C,D; data not shown). Cyclin A2 depletion by itself did not cause as much rereplication as cyclin A2/geminin codepletion, although the cells accumulated in $S$ phase, suggesting that geminin and cyclin $\mathrm{A} 2$ are redundant to each other for preventing rereplication in HeLa cells. In summary, depletion of geminin alone is sufficient for rereplication in HCT116 cells but codepletion of cyclin A and geminin is needed to cause rereplication in HeLa cells. Emil inactivation (and APC/C activation) simultaneously inactivates both of these redundant barriers to rereplication.

\section{Destruction of Cyclin A is required for induction of rereplication by Emi1 RNAi}

To directly test that cyclin A destruction is critical for rereplication after Emil depletion, cyclin A carrying mutations (R47A and L50V) in the destruction-box motif (cyclin $\mathrm{A} 2 \Delta \mathrm{D}$ ) was expressed by a retrovirus vector. While most cyclin A proteins are degraded after Emil RNAi in cells infected with control viruses, a significant amount of cyclin A protein remained in cyclin A2 $\Delta \mathrm{D}$ expressing cells (Fig. 5A). Rereplication after Emil RNAi 
was reduced in the cyclin $\mathrm{A} 2 \Delta \mathrm{D}$-expressing cells (Fig. 5B), although Emil knockdown and decrease of geminin is similar to control cells. Therefore, cyclin A destabilization is important for the rereplication seen after Emil depletion. Geminin was still decreased, again emphasizing that geminin and cyclin A are redundant to each other in blocking rereplication in HeLa cells. Both of them have to be decreased before rereplication is seen.

To rule out a Cdk-independent function of cyclin A, we next tested whether the ability of cyclin A to suppress rereplication requires association with Cdk. Previously, it was demonstrated that a mutation in R211 disrupts interaction between cyclin A and Cdks (Kobayashi et al. 1992). We generated the cyclin $\mathrm{A} \Delta \mathrm{D}(\mathrm{R} 211 \mathrm{~A})$ mutant, in which R211 of cyclin $\mathrm{A} \Delta \mathrm{D}$ is mutated to alanine. Cyclin $\mathrm{A} \Delta \mathrm{D}$ and cyclin $\mathrm{A} \Delta \mathrm{D}(\mathrm{R} 211 \mathrm{~A})$ were expressed at similar levels (Fig. 5A), yet the R211A mutation impaired the ability of cyclin $\mathrm{A} \Delta \mathrm{D}$ to suppress rereplication (Fig. 5B). Therefore, suppression of rereplication by cyclin A requires Cdk association.

\section{Cdk2 and Cdk1 are involved in prevention of rereplication}

The requirement of Cdk interaction implies that cyclin A-Cdk together are involved in prevention of rereplication. To directly test this we examined whether codepletion of Cdks with geminin causes rereplication. Cyclin A is known to interact with the S-phase Cdk, Cdk2, and the M-phase Cdk, Cdk1. We thus cotransfected siRNAs targeting Cdk2, Cdk1, or geminin into synchronized cells using the procedure summarized in Figure 3C. Cells were released from G1/S block by aphidicolin and harvested after 18 or $39 \mathrm{~h}$. Codepletion of geminin, Cdk2, and Cdk 1 proteins in HeLa cells resulted in rereplication after $39 \mathrm{~h}$ (Fig. 6A,B). Codepletion of geminin with either Cdk2 or Cdk1 alone showed only marginal rereplication (data not shown), indicating Cdk1 and Cdk2 plays redundant roles in prevention of rereplication. Collectively, these data suggest that cyclin $\mathrm{A}-\mathrm{Cdk} 2$ and cyclin A-Cdk1 complexes redundantly prevent rereplication in HeLa cells. It is intriguing, in this context, that the high levels of cyclin E in Emil-depleted cells cannot prevent rereplication, because it suggests that cyclin A-Cdk2 and cyclin E-Cdk2 must have different substrate specificities.

\section{Checkpoint pathways are activated in rereplicating cells following Emi1 depletion}

Previously we and others have shown that the DNA damage checkpoint is activated in cells undergoing rereplication after geminin RNAi (Melixetian et al. 2004; Zhu et al. 2004). We thus tested if a similar checkpoint pathway is activated during Emil RNAi-induced rereplication. The DNA damage checkpoint is activated through kinases, ATM or ATR, which in turn activate downstream checkpoint kinases, Chk1 and Chk2, by phosphorylation. Phosphorylation of a histone variant, H2AX, by ATM or ATR is known to be an early event during checkpoint activation. Figure 7A shows that, in Emil-depleted cells, H2AX is phosphorylated at Ser139 and phospho-H2AX forms foci. In addition, phosphorylation of Chk1 at Ser317 was greatly increased and that of Chk2 at Thr68 was also slightly increased (Fig. 7B). These data suggest that rereplication induced by Emil depletion activates the DNA damage checkpoint.

\section{Discussion}

In this paper, we showed that Emil is essential for cell proliferation. Although Emil has been recognized as a factor important for entry into $S$ and $M$ phases in humans, mice, Drosophila, and Xenopus extracts (Reimann et al. 2001; Grosskortenhaus and Sprenger 2002; Hsu et al. 2002; Lee et al. 2006), our data suggest that an essential role of Emil in the cell cycle is prevention of rereplication. At the G1/S transition, Emil is induced by E2F and allows accumulation of cyclin A and geminin, which are two redundant mechanisms for rereplication block (Fig. 8). Until it is degraded via ubiquitination by $\mathrm{SCF}^{\beta-\operatorname{TrCP}}$ in early mitosis, Emil prevents rereplication by maintaining high levels of geminin and cyclin A. A similar role of Emil in preventing rereplication has been independently discovered by Dr. Jonathon Pines (pers. comm.).

Although the effect of Emil depletion was examined in many experimental systems (Grosskortenhaus and Sprenger 2002; Hsu et al. 2002; Lee et al. 2006), the rereplication phenotype has not been reported. A part of the reason is that it is difficult to detect rereplication without analysis of DNA content by FACS, which is hard to perform in flies or mice, especially because Emilnull organisms are embryonic lethal. However, it is im-

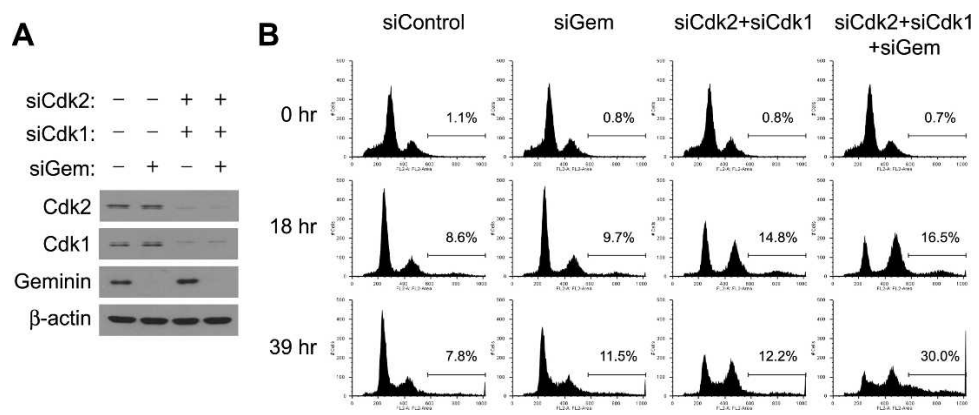

Figure 6. $\mathrm{Cdk} 2$ and $\mathrm{Cdk} 1$ are involved in rereplication block in HeLa. (A) Codepletion of Cdk2, Cdk1, and geminin by RNAi using the protocol in Figure 2C. Cells released from the aphidicolin block for $39 \mathrm{~h}$ were examined by Western blotting. (B) Codepletion of Cdk2, $\mathrm{Cdk} 1$, and geminin induces rereplication in HeLa. Cells treated as in Figure 2C and released for the indicated times were examined by FACS for DNA content. The percentages of cells with $>4 \mathrm{~N}$ DNA are indicated. 
A

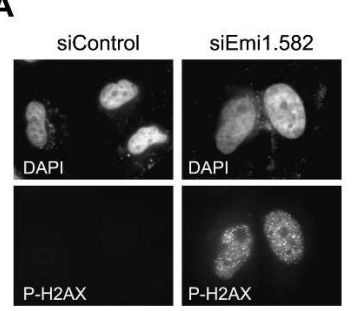

B

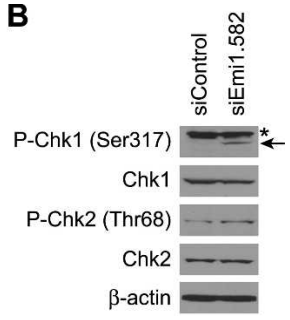

Figure 7. DNA damage checkpoint is activated in Emil-depleted cells. (A) H2AX phosphorylation and foci formation in Emil-depleted HeLa cells. Cells were transfected with the indicated siRNAs for $48 \mathrm{~h}$ and stained with DAPI and anti-phospho-H2AX (Ser139). (P-H2AX) Phospho-H2AX. (B) Phosphorylation of Chk1 and Chk2 after Emil depletion. HeLa cells were transfected with the indicated siRNAs for $48 \mathrm{~h}$ and cell lysates were examined by Western blotting for the indicated proteins. (P-Chk1) Phospho-Chk1; (P-Chk2) phospho-Chk2; (*) a crossreactive band.

portant to note that in the previous studies some of the Emil-deficient cells in flies and in mouse embryos seem to have giant nuclei, a hallmark of rereplication (Grosskortenhaus and Sprenger 2002; Lee et al. 2006). Contrary to our study, Emil RNAi in HeLa cells was reported to cause a failure of cells to enter $\mathrm{S}$ phase (Hsu et al. 2002). This conclusion was drawn from the decrease in the number of cells incorporating BrdU after Emil RNAi. However, reduction in BrdU-positive cells could be due to a decrease in DNA synthesis secondary to rereplication-induced fork stalling or to a cell cycle arrest due to checkpoint activation. Rereplication may have been missed due to the lack of cell cycle analysis by FACS. Alternatively, differences in RNAi efficiency between the two studies may cause differences in the levels of residual Emil, leading to differences in the terminal phenotype.

\section{$A P C / C$ activity and pre- $R C$ formation}

Consistent with its role as an inhibitor of $\mathrm{APC} / \mathrm{C}$, rereplication after Emil depletion requires APC/C. Since Cdc20 itself is an APC/C substrate (Pfleger and Kirschner 2000), under Emil-depleted conditions, the active $\mathrm{APC} / \mathrm{C}$ mainly contains Cdh1. APC/ $\mathrm{C}^{\mathrm{Cdh} 1}$ is normally active in late $\mathrm{M}$ and $\mathrm{G} 1$ phases, and prevents accumulation of mitotic cyclins and geminin (Irniger and Nasmyth 1997; McGarry and Kirschner 1998). APC/C activity is important for allowing pre-RC formation in G1. Overexpression of geminin lacking a destruction box inhibited pre-RC formation and impaired DNA replication (Shreeram et al. 2002; Wohlschlegel et al. 2002). Similarly, premature appearance of cyclins in G1 is deleterious to pre-RC formation (Coverley et al. 2002; EkholmReed et al. 2004). Thus, high APC/C activity and the attendant decrease in geminin and cyclin A are necessary to allow pre-RC formation in late M and G1 phases. Our results suggest that the converse is also true: Low $\mathrm{APC} / \mathrm{C}$ activity prevents pre-RC formation in S and G2 and prevents rereplication. Overexpression of Cdh1 has been reported to cause overreplication (Sorensen et al. 2000). Taken together, our results suggest that Emil plays a critical role in prevention of rereplication as a regulator of APC/C activity in S and G2 phases.

\section{Geminin and Cdk as redundant mechanisms for rereplication block}

While a role of geminin in preventing rereplication in mammalian cells is well accepted, we show that in some cell lines, cyclin A is equally important. The role of cyclin A in prevention of rereplication is dependent on Cdks. The importance of high Cdk activity in prevention of rereplication is well established in yeasts (cited in the introduction). However, it has been unclear whether Cdk prevents rereplication in mammalian cells or Xenopus egg extracts because alteration of the geminin-Cdt 1 balance alone was sufficient to induce rereplication, without any manipulation of the Cdk activity seen in S-phase cells or extracts (Melixetian et al. 2004; Zhu et al. 2004; Arias and Walter 2005). On the other hand, a negative effect of Cdk activity on mammalian pre-RC components has also been reported. For example, Cdkdependent phosphorylation causes nuclear export of excess Cdc6 protein in human cells (Saha et al. 1998; Fujita et al. 1999; Jiang et al. 1999; Petersen et al. 1999). Phosphorylation of Cdt 1 by Cdk targets Cdt1 for polyubiquitination by $\mathrm{SCF}^{\text {Skp2 }}$ and degradation (Liu et al. 2004; Sugimoto et al. 2004). Overexpression of Cdt1 mutated in a Cy motif that is required for phosphorylation by $\mathrm{Cdk} 2$ increases rereplication, supporting the negative effect of Cdks on pre-RC formation (Takeda et al. 2005; Nishitani et al. 2006). In addition, Cdk1 inactivation in a mammalian fibrosarcoma cell line causes rereplication (Itzhaki et al. 1997). In the face of this conflicting evidence of the critical role of geminin or Cdk in rereplication block in vertebrates, it was unclear whether geminin and Cdk are redundant in rereplication block or nonredundant, and function in different phases of the cell cycle. Our study suggests that geminin and Cdk provide redundant mechanisms for preventing rereplication in S and G2 phases, although there is a difference between cell lines (see below). Collectively, we propose a

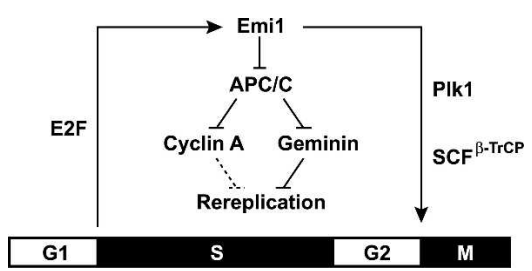

Figure 8. Suppression of rereplication by Emi1 during S and G2 phases. Rereplication block pathways triggered by Emil. Emil is induced at G1/S transition by E2F and inhibits APC/C to stabilize rereplication inhibitors, cyclin A and geminin. Emil is degraded upon mitotic entry after phosphorylation by Plk and ubiquitination by $\mathrm{SCF}^{\beta-\mathrm{TrCP}}$. In some cancer cells-e.g., HCT116-cyclin A-dependent suppression of rereplication is not functional (shown by dashed lines). 
model that the cyclin A-Cdk complex and geminin independently prevent rereplication by inhibiting formation of pre-RCs, and both pathways are coregulated by Emil during $\mathrm{S}$ and G2 phases.

\section{Difference in rereplication block pathways between cell lines}

A redundant role of cyclin A and geminin in preventing rereplication in some cell lines explains the puzzling failure to see rereplication after depletion of geminin in commonly studied cells like HeLa. The presence of two redundant pathways to prevent rereplication is also consistent with the results of $\mathrm{H}$. Hochegger and S. Takeda (pers. comm.). They showed that Cdk inhibition in the chicken DT40 cell line causes rereplication in mitosis but not in G2 phase, indicating the presence of at least one other pathway to prevent rereplication in G2 cells that is neutralized by the activation of APC/C in mitosis. On the other hand, in a Drosophila cell line, geminin and cyclin A are nonredundant in this aspect, so that depletion of either protein leads to rereplication (Mihaylov et al. 2002). Similarly, we and others have shown that depletion of geminin alone leads to rereplication in HCT116 colon cancer cell lines while overexpression of Cdt1 promotes rereplication in lung cancer cells (Vaziri et al. 2003; Takeda et al. 2005). Thus, rereplicationblocking pathways are different between tissues, developmental stages, or types of cancer cells with geminin being the sole inhibitor in some but not all cells. Further study will be required to determine why cyclin $\mathrm{A}$ is not able to suppress rereplication in the absence of geminin in HCT116 cells or upon overexpression of Cdt1 in lung cancer cells.

Activation of DNA damage checkpoint after rereplication suggests that rereplication leads to DNA damage or unusual DNA structures. Indeed, a recent study suggested that uncontrolled rereplication causes fork collisions and results in DNA fragmentation in Xenopus egg extracts (Davidson et al. 2006). Therefore, it will be important to examine the effect of rereplication on genome integrity and its potential as a cause of tumorigenesis. In this sense, it is worth noting that overexpression of Cdt1 or Cdc6, which tilts the balance of origin licensing toward rereplication (Vaziri et al. 2003), is associated with genomic instability and poor prognosis in lung cancers and mantle cell lymphoma (Karakaidos et al. 2004; Magda Pinyol et al. 2006). In addition, the lack of the Cdk-dependent rereplication block pathway in HCT116 reported in this study suggests that loss of some but not all rereplication-blocking pathways may be seen in cancer cells, predisposing them to genomic instability. Emil overexpression has been reported to accompany genomic instability, and Emil is overexpressed in tumors (Hsu et al. 2002; Lehman et al. 2006). Our results suggest, however, that deregulation of APC activity through functional inactivation of Emil might also contribute to genome instability in cancer cells. Finally, given that Emil regulates two redundant mechanisms for preventing rereplication, we speculate that inactivation of Emil may be important in physiological situations where vertebrate cells undergo endoreduplication as part of normal development.

\section{Materials and methods}

Plasmids

A coding sequence of human cyclin A2 and Emil was cloned into a retrovirus vector pMMP-puro (Pulsipher et al. 1998) and pMSCVpuro (Clontech), respectively, and mutagenesis was performed using QuickChange kit (Stratagene) according to the manufacturer's instructions. Mutations that confer resistance to siEmil.582 were introduced to the Emil coding sequence using primers $5^{\prime}$-GAAGAAGGTAGCCTCCTCGAGGAAAA CTTTGGAGATAGCCTCCAATCCTGCCTGCTACAAATAC-3' and 5'-GTATTTGTAGCAGGCAGGATTGGAGGCTATCTCC AAAGTTTTCCTCGAGGAGGCTACCTTCTTC-3' .

\section{Cell culture, retrovirus infection, and FACS}

HeLa cells were cultured in DMEM containing $10 \%$ donor calf serum. HCT116 cells were cultured in McCoy's 5A containing $10 \%$ fetal calf serum. MCF10A is an immortalized breast epithelial cell line derived from fibrocystic disease that was cultured in DMEM/F12 containing 5\% donor calf serum, $0.02 \mu \mathrm{g} /$ $\mathrm{mL}$ EGF (Sigma), $1 \mu \mathrm{g} / \mathrm{mL}$ Insulin (Sigma), $1.4 \mu \mathrm{M}$ hydrocortisone (Sigma), and $0.1 \mu \mathrm{g} / \mathrm{mL}$ Cholera toxin. For synchronization of cells in mitosis, cells were treated with $40 \mathrm{ng} / \mathrm{mL}$ of Nocodazole for $8 \mathrm{~h}$ and rounded cells were collected. For synchronization of cells at $\mathrm{G} 1 / \mathrm{S}$, aphidicolin $(1 \mu \mathrm{g} / \mathrm{mL})$ was added to the medium. Cells were released from the block by extensive washing with PBS. Retroviruses were produced in the 293GPG cell line (Ory et al. 1996) or the Phoenix cell line (Pear et al. 1993) by transient transfection of retrovirus plasmids. Cells were infected with retroviral supernatants and selected in puromycin (1 $\mu \mathrm{g} / \mathrm{mL}$ ). FACS analysis was performed as described previously (Machida et al. 2005b).

\section{RNAi screening}

RNAi screening for genes involved in cell proliferation was performed as described previously (Machida et al. 2006). Single siRNA oligos were designed against human F-box proteins based on the criteria reported previously (Reynolds et al. 2004) and purchased from Samchuly. Five-thousand MCF10A cells were transfected with 4 pmol of siRNA duplex using Lipofectamine 2000 (Invitrogen) in a 96-well plate. After a 3-d culture, cells were incubated with $10 \mu \mathrm{M}$ BrdU for $15 \mathrm{~min}$ and incorporation of BrdU per well was measured by ELISA using HRPcoupled anti-BrdU antibody (Roche). The screen was performed with three technical replicates and repeated twice. Genes whose knockdown reduced BrdU incorporation as much as a positive control siRNA (targeting a replication factor, ORC2) were considered as hits. siControl, which targets a luciferase gene, was used as a negative control. For FBXO5/Emil, a hit gene in the primary siRNA screen, additional siRNA duplexes were designed against different sequences of the mRNA and used for the secondary siRNA screen.

\section{RNAi}

siRNA transfection was performed using Oligofectamine (Invitrogen) as described previously (Machida et al. 2005b). Lipofectamine RNAiMAX (Invitrogen) was used for siRNA transfection 
into Nocodazole-arrested cells. The target sequences of siRNAs were as follows: siControl (GL2), 5'-AACGUACGCGGA AUACUUCGA-3'; siEmi1.582, 5'-GAGAAUUUCGGUGACA GUCUA-3'; siEmi1.1298， 5'-UACGAAGUGUCUCUGUAA UUA-3'; siEmi1.1411，5'-UACGAAGAUUGUGAUCUCUUA -3'; siCyclin A2, 5' -AAAGCUGGCCUGAAUCAUUAA-3'; and siCdk 1 , 5'-AAAGGAACTTCGTCATCCAAA-3'. The sequences of Geminin, Cdk2, Cdh1, Cdc20, and ORC2 siRNAs were reported previously (Brummelkamp et al. 2002; Bashir et al. 2004; Zhang et al. 2004; Zhu et al. 2004; Machida et al. 2005b).

Experimental scheme of RNAi in cells synchronized in mitosis (Fig. 3): HeLa cells were synchronized in metaphase by Nocodazole treatment $(40 \mathrm{ng} / \mathrm{mL})$ for $8 \mathrm{~h}$. Rounded cells were collected, transfected with siRNAs, and released into aphidicolin for $24 \mathrm{~h}$. Cells were released from the aphidicolin block, and samples were taken after indicated times in Figure 3, E and F.

\section{Western blotting}

For Western blotting, cells were lysed in lysis buffer $(50 \mathrm{mM}$ Tris-HCl, $150 \mathrm{mM} \mathrm{NaCl}$, 0.1\% NP-40, $5 \mathrm{mM}$ EDTA) supplemented with protease inhibitor mix (Sigma). The antibodies used were anti-Emil (Invitrogen); anti-cyclin E, anti-cyclin A, anti-cyclin B1, anti-Cdk2, anti-Cdk1, anti-Cdc20, and antiCdc6 (Santa Cruz Biotechnology); anti-Cdh1 (BD Biosciences); anti- $\beta$-actin and anti-Chk2 (Sigma); anti-Chk1, anti-phosphoChk1 (Ser317), anti-phospho-Chk2 (Thr68) (Cell Signaling Technology). Rabbit anti-geminin antiserum was reported previously (Wohlschlegel et al. 2000).

\section{Immunostaining}

Cells cultured on slides were fixed with $4 \%$ paraformaldehyde for $10 \mathrm{~min}$ and permeabilized with $0.2 \%$ TX-100 for $10 \mathrm{~min}$. Following blocking with $3 \%$ BSA in PBS for $1 \mathrm{~h}$, cells were incubated with antibodies diluted in PBS containing 3\% BSA for $1 \mathrm{~h}$. After three washes with PBS, cells were incubated with FITC-labeled anti-rabbit IgG antibody (DAKO) diluted in PBS containing $3 \%$ BSA for $30 \mathrm{~min}$ and washed three times with PBS. Cells were mounted with Vectashield containing DAPI (Vector Laboratory). The antibodies used were anti-phosphohistone H3 (Ser10) antibody (Millipore) and anti-phospho-H2AX (Ser139) (Cell Signaling Technology).

\section{Acknowledgments}

We thank members of the Dutta laboratory for helpful discussions. This work was supported by RO1 CA60499.

\section{References}

Arias, E.E. and Walter, J.C. 2005. Replication-dependent destruction of Cdt1 limits DNA replication to a single round per cell cycle in Xenopus egg extracts. Genes \& Dev. 19: $114-126$

Bashir, T., Dorrello, N.V., Amador, V., Guardavaccaro, D., and Pagano, M. 2004. Control of the SCF(Skp2-Cks1) ubiquitin ligase by the $\mathrm{APC} / \mathrm{C}(\mathrm{Cdh} 1)$ ubiquitin ligase. Nature 428: 190-193.

Brummelkamp, T.R., Bernards, R., and Agami, R. 2002. A system for stable expression of short interfering RNAs in mammalian cells. Science 296: 550-553.

Correa-Bordes, J. and Nurse, P. 1995. p25rum1 orders S phase and mitosis by acting as an inhibitor of the p34cdc2 mitotic kinase. Cell 83: 1001-1009.

Coverley, D., Laman, H., and Laskey, R.A. 2002. Distinct roles for cyclins $\mathrm{E}$ and A during DNA replication complex assembly and activation. Nat. Cell Biol. 4: 523-528.

Davidson, I.F., Li, A., and Blow, J.J. 2006. Deregulated replication licensing causes DNA fragmentation consistent with head-to-tail fork collision. Mol. Cell 24: 433-443.

Ekholm-Reed, S., Mendez, J., Tedesco, D., Zetterberg, A., Stillman, B., and Reed, S.I. 2004. Deregulation of cyclin E in human cells interferes with prereplication complex assembly. J. Cell Biol. 165: 789-800.

Fang, G., Yu, H., and Kirschner, M.W. 1998. Direct binding of CDC20 protein family members activates the anaphase-promoting complex in mitosis and G1. Mol. Cell 2: 163-171.

Fujita, M., Yamada, C., Goto, H., Yokoyama, N., Kuzushima, K., Inagaki, M., and Tsurumi, T. 1999. Cell cycle regulation of human CDC6 protein. Intracellular localization, interaction with the human mom complex, and CDC2 kinase-mediated hyperphosphorylation. I. Biol. Chem. 274: 25927-25932.

Glotzer, M., Murray, A.W., and Kirschner, M.W. 1991. Cyclin is degraded by the ubiquitin pathway. Nature 349: 132-138.

Gonzalez, M.A., Tachibana, K.E., Adams, D.J., van der Weyden, L., Hemberger, M., Coleman, N., Bradley, A., and Laskey, R.A. 2006. Geminin is essential to prevent endoreduplication and to form pluripotent cells during mammalian development. Genes \& Dev. 20: 1880-1884.

Grosskortenhaus, R. and Sprenger, F. 2002. Rcal inhibits APC$\mathrm{Cdh} 1(\mathrm{Fzr})$ and is required to prevent cyclin degradation in G2. Dev. Cell 2: 29-40.

Guardavaccaro, D., Kudo, Y., Boulaire, J., Barchi, M., Busino, L., Donzelli, M., Margottin-Goguet, F., Jackson, P.K., Yamasaki, L., and Pagano, M. 2003. Control of meiotic and mitotic progression by the F box protein $\beta$-Trcpl in vivo. Dev. Cell 4: 799-812.

Hansen, D.V., Loktev, A.V., Ban, K.H., and Jackson, P.K. 2004. Plk1 regulates activation of the anaphase promoting complex by phosphorylating and triggering SCF $\beta T$ TrCP-dependent destruction of the APC Inhibitor Emil. Mol. Biol. Cell 15: 5623-5634.

Hendzel, M.J., Wei, Y., Mancini, M.A., Van Hooser, A., Ranalli, T., Brinkley, B.R., Bazett-Jones, D.P., and Allis, C.D. 1997. Mitosis-specific phosphorylation of histone $\mathrm{H} 3$ initiates primarily within pericentromeric heterochromatin during G2 and spreads in an ordered fashion coincident with mitotic chromosome condensation. Chromosoma 106: 348-360.

Hsu, J.Y., Reimann, J.D., Sorensen, C.S., Lukas, J., and Jackson, P.K. 2002. E2F-dependent accumulation of hEmil regulates S phase entry by inhibiting APC(Cdh1). Nat. Cell Biol. 4: 358-366.

Irniger, S. and Nasmyth, K. 1997. The anaphase-promoting complex is required in G1 arrested yeast cells to inhibit B-type cyclin accumulation and to prevent uncontrolled entry into S-phase. J. Cell Sci. 110: 1523-1531.

Itzhaki, J.E., Gilbert, C.S., and Porter, A.C. 1997. Construction by gene targeting in human cells of a 'conditional' CDC2 mutant that rereplicates its DNA. Nat. Genet. 15: 258-265.

Jiang, W., Wells, N.J., and Hunter, T. 1999. Multistep regulation of DNA replication by Cdk phosphorylation of HsCde6. Proc. Natl. Acad. Sci. 96: 6193-6198.

Jin, J., Cardozo, T., Lovering, R.C., Elledge, S.J., Pagano, M., and Harper, J.W. 2004. Systematic analysis and nomenclature of mammalian F-box proteins. Genes \& Dev. 18: 2573-2580.

Karakaidos, P., Taraviras, S., Vassiliou, L.V., Zacharatos, P., Kastrinakis, N.G., Kougiou, D., Kouloukoussa, M., Nishitani, H., Papavassiliou, A.G., Lygerou, Z., et al. 2004. Over- 
expression of the replication licensing regulators hCdt 1 and hCdc6 characterizes a subset of non-small-cell lung carcinomas: Synergistic effect with mutant p53 on tumor growth and chromosomal instability-Evidence of E2F-1 transcriptional control over hCdt1. Am. J. Pathol. 165: 1351-1365.

Kobayashi, H., Stewart, E., Poon, R., Adamczewski, J.P., Gannon, J., and Hunt, T. 1992. Identification of the domains in cyclin A required for binding to, and activation of, p34cdc2 and p32cdk2 protein kinase subunits. Mol. Biol. Cell 3: 1279-1294.

Lee, H., Lee, D.J., Oh, S.P., Park, H.D., Nam, H.H., Kim, J.M., and Lim, D.S. 2006. Mouse emil has an essential function in mitotic progression during early embryogenesis. Mol. Cell. Biol. 26: 5373-5381.

Lehman, N.L., Verschuren, E.W., Hsu, J.Y., Cherry, A.M., and Jackson, P.K. 2006. Overexpression of the anaphase promoting complex/cyclosome inhibitor Emil leads to tetraploidy and genomic instability of p53-deficient cells. Cell Cycle 5: 1569-1573.

Liu, E., Li, X., Yan, F., Zhao, Q., and Wu, X. 2004. Cyclindependent kinases phosphorylate human Cdt1 and induce its degradation. J. Biol. Chem. 279: 17283-17288.

Lukas, C., Sorensen, C.S., Kramer, E., Santoni-Rugiu, E., Lindeneg, C., Peters, J.M., Bartek, J., and Lukas, J. 1999. Accumulation of cyclin B1 requires E2F and cyclin-A-dependent rearrangement of the anaphase-promoting complex. Nature 401: 815-818.

Machida, Y.J., Hamlin, J.L., and Dutta, A. 2005a. Right place, right time, and only once: Replication initiation in metazoans. Cell 123: 13-24.

Machida, Y.J., Teer, J.K., and Dutta, A. 2005b. Acute reduction of an origin recognition complex (ORC) subunit in human cells reveals a requirement of ORC for Cdk2 activation. $J$. Biol. Chem. 280: 27624-27630.

Machida, Y.J., Chen, Y., Machida, Y., Malhotra, A., Sarkar, S., and Dutta, A. 2006. Targeted comparative RNA interference analysis reveals differential requirement of genes essential for cell proliferation. Mol. Biol. Cell 17: 4837-4845.

Magda Pinyol, I.S., Silvia, B., Fernandez, V., Colomo, L., Campo, E., and Jares, E. 2006. Unbalanced expression of licensing DNA replication factors occurs in a subset of mantle cell lymphomas with genomic instability. Int. J. Cancer 119: 2768-2774.

Mailand, N. and Diffley, J.F. 2005. CDKs promote DNA replication origin licensing in human cells by protecting Cde6 from APC/C-dependent proteolysis. Cell 122: 915-926.

Margottin-Goguet, F., Hsu, J.Y., Loktev, A., Hsieh, H.M., Reimann, J.D., and Jackson, P.K. 2003. Prophase destruction of Emil by the $S C F(\beta \operatorname{TrCP} /$ Slimb) ubiquitin ligase activates the anaphase promoting complex to allow progression beyond prometaphase. Dev. Cell 4: 813-826.

McGarry, T.J. and Kirschner, M.W. 1998. Geminin, an inhibitor of DNA replication, is degraded during mitosis. Cell 93: 1043-1053.

Melixetian, M., Ballabeni, A., Masiero, L., Gasparini, P., Zamponi, R., Bartek, J., Lukas, J., and Helin, K. 2004. Loss of Geminin induces rereplication in the presence of functional p53. J. Cell Biol. 165: 473-482.

Mihaylov, I.S., Kondo, T., Jones, L., Ryzhikov, S., Tanaka, J., Zheng, J., Higa, L.A., Minamino, N., Cooley, L., and Zhang, H. 2002. Control of DNA replication and chromosome ploidy by geminin and cyclin A. Mol. Cell. Biol. 22: 18681880.

Moshe, Y., Boulaire, J., Pagano, M., and Hershko, A. 2004. Role of Polo-like kinase in the degradation of early mitotic inhibitor 1 , a regulator of the anaphase promoting complex/cyclo- some. Proc. Natl. Acad. Sci. 101: 7937-7942.

Nguyen, V.Q., Co, C., and Li, J.J. 2001. Cyclin-dependent kinases prevent DNA re-replication through multiple mechanisms. Nature 411: 1068-1073.

Nishitani, H., Sugimoto, N., Roukos, V., Nakanishi, Y., Saijo, M., Obuse, C., Tsurimoto, T., Nakayama, K.I., Nakayama, K., Fujita, M., et al. 2006. Two E3 ubiquitin ligases, SCFSkp2 and DDB1-Cul4, target human Cdt1 for proteolysis. EMBO J. 25: 1126-1136.

Ory, D.S., Neugeboren, B.A., and Mulligan, R.C. 1996. A stable human-derived packaging cell line for production of high titer retrovirus/vesicular stomatitis virus $G$ pseudotypes. Proc. Natl. Acad. Sci. 93: 11400-11406.

Pear, W.S., Nolan, G.P., Scott, M.L., and Baltimore, D. 1993. Production of high-titer helper-free retroviruses by transient transfection. Proc. Natl. Acad. Sci. 90: 8392-8396.

Petersen, B.O., Lukas, J., Sorensen, C.S., Bartek, J., and Helin, K. 1999. Phosphorylation of mammalian CDC6 by cyclin A/CDK2 regulates its subcellular localization. EMBO J. 18: 396-410.

Pfleger, C.M. and Kirschner, M.W. 2000. The KEN box: An APC recognition signal distinct from the D box targeted by Cdh1. Genes \& Dev. 14: 655-665.

Pulsipher, M., Kupfer, G.M., Naf, D., Suliman, A., Lee, J.S., Jakobs, P., Grompe, M., Joenje, H., Sieff, C., Guinan, E., et al. 1998. Subtyping analysis of Fanconi anemia by immunoblotting and retroviral gene transfer. Mol. Med. 4: 468-479.

Reimann, J.D., Freed, E., Hsu, J.Y., Kramer, E.R., Peters, J.M., and Jackson, P.K. 2001. Emil is a mitotic regulator that interacts with Cdc20 and inhibits the anaphase promoting complex. Cell 105: 645-655.

Reynolds, A., Leake, D., Boese, Q., Scaringe, S., Marshall, W.S., and Khvorova, A. 2004. Rational siRNA design for RNA interference. Nat. Biotechnol. 22: 326-330.

Saha, P., Chen, J., Thome, K.C., Lawlis, S.J., Hou, Z.H., Hendricks, M., Parvin, J.D., and Dutta, A. 1998. Human CDC6/ Cdc18 associates with Orcl and cyclin-cdk and is selectively eliminated from the nucleus at the onset of $S$ phase. Mol. Cell. Biol. 18: 2758-2767.

Shreeram, S., Sparks, A., Lane, D.P., and Blow, J.J. 2002. Cell type-specific responses of human cells to inhibition of replication licensing. Oncogene 21: 6624-6632.

Sorensen, C.S., Lukas, C., Kramer, E.R., Peters, J.M., Bartek, J., and Lukas, J. 2000. Nonperiodic activity of the human anaphase-promoting complex-Cdh1 ubiquitin ligase results in continuous DNA synthesis uncoupled from mitosis. Mol. Cell. Biol. 20: 7613-7623.

Sorensen, C.S., Lukas, C., Kramer, E.R., Peters, J.M., Bartek, J., and Lukas, J. 2001. A conserved cyclin-binding domain determines functional interplay between anaphase-promoting complex-Cdh1 and cyclin A-Cdk2 during cell cycle progression. Mol. Cell. Biol. 21: 3692-3703.

Sudo, T., Ota, Y., Kotani, S., Nakao, M., Takami, Y., Takeda, S., and Saya, H. 2001. Activation of Cdh1-dependent APC is required for G1 cell cycle arrest and DNA damage-induced G2 checkpoint in vertebrate cells. EMBO J. 20: 6499-6508.

Sugimoto, N., Tatsumi, Y., Tsurumi, T., Matsukage, A., Kiyono, T., Nishitani, H., and Fujita, M. 2004. Cdt1 phosphorylation by cyclin A-dependent kinases negatively regulates its function without affecting geminin binding. J. Biol. Chem. 279: 19691-19697.

Tada, S., Li, A., Maiorano, D., Mechali, M., and Blow, J.J. 2001. Repression of origin assembly in metaphase depends on inhibition of RLF-B/Cdt1 by geminin. Nat. Cell Biol. 3: 107113.

Takeda, D.Y., Parvin, J.D., and Dutta, A. 2005. Degradation of 
Cdt1 during S phase is Skp2-independent and is required for efficient progression of mammalian cells through $S$ phase. J. Biol. Chem. 280: 23416-23423.

Vaziri, C., Saxena, S., Jeon, Y., Lee, C., Murata, K., Machida, Y., Wagle, N., Hwang, D.S., and Dutta, A. 2003. A p53-dependent checkpoint pathway prevents rereplication. Mol. Cell 11: 997-1008.

Wilmes, G.M., Archambault, V., Austin, R.J., Jacobson, M.D., Bell, S.P., and Cross, F.R. 2004. Interaction of the S-phase cyclin Clb5 with an 'RXL' docking sequence in the initiator protein Orc6 provides an origin-localized replication control switch. Genes \& Dev. 18: 981-991.

Wohlschlegel, J.A., Dwyer, B.T., Dhar, S.K., Cvetic, C., Walter, J.C., and Dutta, A. 2000. Inhibition of eukaryotic DNA replication by geminin binding to Cdt1. Science 290: 2309-2312.

Wohlschlegel, J.A., Kutok, J.L., Weng, A.P., and Dutta, A. 2002. Expression of geminin as a marker of cell proliferation in normal tissues and malignancies. Am. J. Pathol. 161: 267273.

Zhang, G.J., Safran, M., Wei, W., Sorensen, E., Lassota, P., Zhelev, N., Neuberg, D.S., Shapiro, G., and Kaelin Jr., W.G. 2004. Bioluminescent imaging of Cdk2 inhibition in vivo. Nat. Med. 10: 643-648.

Zhu, W., Chen, Y., and Dutta, A. 2004. Rereplication by depletion of geminin is seen regardless of p53 status and activates a G2/M checkpoint. Mol. Cell. Biol. 24: 7140-7150. 


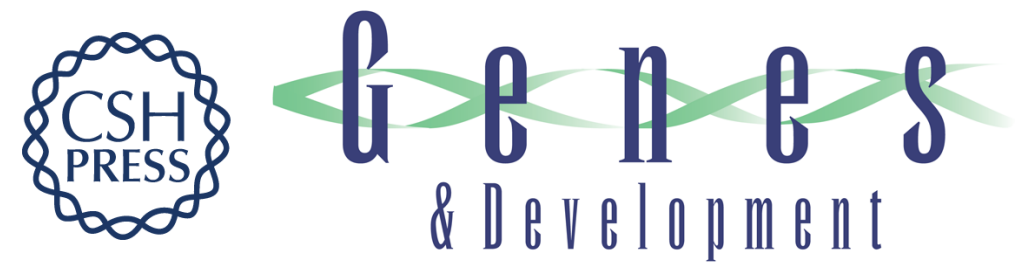

\section{The APC/C inhibitor, Emi1, is essential for prevention of rereplication}

Yuichi J. Machida and Anindya Dutta

Genes Dev. 2007, 21:

Access the most recent version at doi:10.1101/gad.1495007

Supplemental

Material

References This article cites 59 articles, 30 of which can be accessed free at: http://genesdev.cshlp.org/content/21/2/184.full.html\#ref-list-1

\section{License}

Email Alerting Service right corner of the article or click here.
http://genesdev.cshlp.org/content/suppl/2007/01/18/21.2.184.DC1

Receive free email alerts when new articles cite this article - sign up in the box at the top

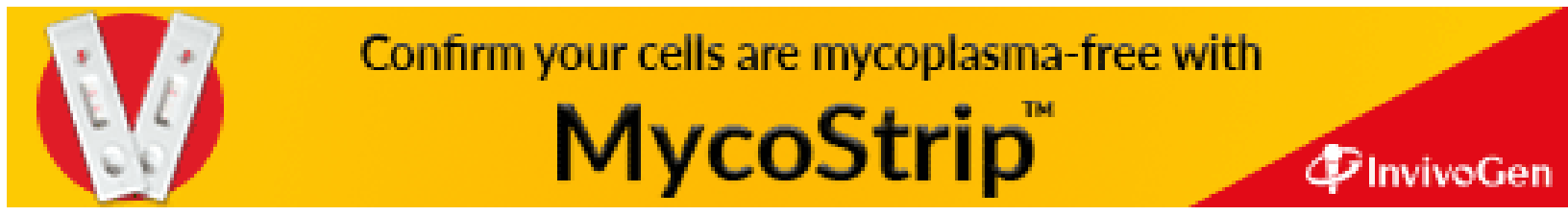

